\title{
Edgard Quinet, Lettres à sa mère (1826-1830)
}

\section{Laurence Richer}

\section{(2) OpenEdition}

\section{Journals}

\section{Édition électronique}

URL : http://journals.openedition.org/studifrancesi/36442

DOI : 10.4000/studifrancesi.36442

ISSN : 2427-5856

\section{Éditeur}

Rosenberg \& Sellier

\section{Édition imprimée}

Date de publication : 1 juillet 2005

Pagination : 186

ISSN : 0039-2944

\section{Référence électronique}

Laurence Richer, «Edgard Quinet, Lettres à sa mère (1826-1830)», Studi Francesi [En ligne], 145 (XLIX I

I) | 2005, mis en ligne le 30 novembre 2015, consulté le 20 avril 2021. URL : http://

journals.openedition.org/studifrancesi/36442 ; DOI : https://doi.org/10.4000/studifrancesi.36442

Ce document a été généré automatiquement le 20 avril 2021.

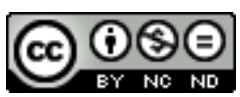

Studi Francesi è distribuita con Licenza Creative Commons Attribuzione - Non commerciale - Non opere derivate 4.0 Internazionale. 


\title{
Edgard Quinet, Lettres à sa mère (1826-1830)
}

\author{
Laurence Richer
}

\section{RÉFÉRENCE}

EDGARD QUINET, Lettres à sa mère (1826-1830), éditées par Simone BERNARD-GRIFFITHS et Gerard PEYLET, Paris, Honoré Champion, 2003, t. III, pp. 214.

Ce troisième tome recouvre un moment essentiel de la vie de Quinet. On y retrouve le fort lien intellectuel et affectif existant entre Eugénie Quinet et son fils dans des passages dont le lyrisme, hérité des Lumières, est aussi romantique. Mais c'est surtout le moment où Quinet, qui achève de traduire Herder, met en place une pensée où l'homme trouve sa place dans la chaîne des temps, sans abdiquer sa liberté. C'est tout naturellement que, rencontrant le Rhin, il écrit: «il me fait penser à tout ce qu'il y a d'illimité dans l'histoire» (lettre du 7 octobre 1826). Le séjour à Heidelberg le met en contact avec le romantisme allemand et donne à sa pensée cette dimension européenne qui restera la spécificité d'un des pères de la littérature comparée. Ce grand musicien découvre aussi en Allemagne des compositeurs peu connus de lui, et l'on ne sait trop, quand il écoute l'oratorio Samson de Haendel, s'il tombe amoureux de cette musique, ou de la chanteuse qui va devenir sa femme. La qualité lyrique des grandes œuvres à venir, comme Ahasvérus, se forme alors selon des processus que cette correspondance aide à dégager. Très riche sur la formation de l'écrivain, ce tome est plus décevant pour l'approche politique, et il ne faut pas y chercher une vue spectaculaire de la révolution de 1830. Toutefois un des aspects les plus intéressants du livre est la recherche d'une carrière par Quinet, qui en dit long sur la progressive mise en place d'une administration démocratique en France, et se termine par sa nomination comme professeur. Les portraits de Guizot, Cousin et Villemain complètent ce qui en apparaît dans la correspondance avec Michelet. 
2 L'apparat critique, abondant, est destiné aussi bien à un large public qu'aux universitaires. Ce parti pris est justifié par le contenu de ces lettres, qui peut intéresser un lectorat divers. En l'absence des lettres de la correspondante, les éditeurs publient en annexe quelques lettres de Quinet sur la même période. Reposant sur une copie peu sûre faite par la seconde madame Quinet, elles apportent néanmoins un éclairage complémentaire qui ajoute à la signification de l'ensemble. 